\title{
Fatty acid transformation in zooplankton: from seston to benthos
}

\author{
Peter Tiselius ${ }^{1, *}$, Benni Winding Hansen ${ }^{2}$, Danilo Calliari ${ }^{1,3}$ \\ ${ }^{1}$ Department of Marine Ecology-Kristineberg, University of Gothenburg, 45178 Fiskebäckskil, Sweden \\ ${ }^{2}$ Department of Environmental, Social and Spatial Change, Roskilde University, 4000 Roskilde, Denmark \\ ${ }^{3}$ Present address: Facultad de Ciencias, Universidad de la República, CP 11400, Montevideo, Uruguay
}

\begin{abstract}
All organic matter, fatty acids (FA) in particular, is transformed in the pelagic plankton food web before reaching fishes or benthic organisms. Mesozooplankton (0.2 to $2 \mathrm{~mm}$ ) is the main conduit for FA transfer, and FA profiles in sedimenting matter should therefore be significantly affected by its activity. To test this hypothesis, we sampled seston, zooplankton and sediment trap material for FA analysis during 5 campaigns spanning 4 seasons at a coastal site on the west coast of Sweden. Saturated (SAFAs) and monounsaturated (MUFAs) FAs dominated seston and trap material, while copepods contained 75 to $90 \%$ polyunsaturated FAs (PUFAs). Sedimentation of bulk particulate organic carbon did not vary significantly with season (coefficient of variation, $\mathrm{CV}=33 \%)$, while pigment $(\mathrm{CV}=49 \%)$ and in particular faecal pellet fluxes $(\mathrm{CV}=100 \%)$ were highly variable as a result of copepod feeding activity. Copepod feeding, pellet production and egg production were all high after the spring bloom and in summer and autumn. Overall, 5 to $25 \%$ of the sedimenting FAs were affected by copepod feeding activities, and the supply of PUFAs to the benthos was significantly enhanced by copepod grazing activity. SAFAs and MUFAs were enriched by 5 to $10 \%$ in sediment traps, while the proportion of the most important PUFA, docosahexaenoic acid, was reduced by up to $15 \%$ in summer and autumn. In conclusion, the periods of significant input of PUFAs to the sediment coincide with the period of highest transformation by the mesozooplankton, which in the present study was summer and autumn.
\end{abstract}

KEY WORDS: Copepeods - Polyunsaturated fatty acid - PUFA - Sediment traps - Grazing · Docosahexaenoic acid $\cdot$ DHA $\cdot$ Lipid $\cdot$ Egg production

Resale or republication not permitted without written consent of the publisher

\section{INTRODUCTION}

Zooplankton is a major transformer of the carbon fixed by phytoplankton, and copepods are the most important group for this task. The grazing and metabolism of copepods will change the quality of the organic matter by accumulating essential constituents for growth and reproduction of fish (e.g. Fenchel 1988). Indeed, zooplankton has a completely different fatty acid (FA) profile than its food (e.g. Cotonnec et al. 2001, Persson \& Vrede 2006).

The FAs in seston are dominated by $\mathrm{C} 16$ and $\mathrm{C} 18$ saturated FAs (SAFAs) and lower amounts of mono- unsaturated (MUFAs) and polyunsaturated (PUFAs) FAs. However, there are strong seasonal changes related to phytoplankton biomass and composition, with the highest amount of PUFA ( $>50 \%$ ) found during blooms (Mayzaud et al. 1989, Skerratt et al. 1995, Reuss \& Poulsen 2002, Parrish et al. 2005, Leu et al. 2006). The relative amount of PUFA in seston has been shown to decline with depth (Parrish et al. 2005), and bacterial breakdown (Kaneda 1991), autoxidation (Ding \& Sun 2005) and zooplankton grazing are potential reasons for this transformation. Copepods are involved in all of these processes, since they enhance the vertical transfer through re- 
packaging the organic material into faecal pellets (Kiørboe 1993) and they also degrade the quality of sedimenting organic matter by assimilation and metabolism.

Coastal waters are more productive than open oceans mainly due to the larger input of nutrients from land, which enhance the phytoplankton growth. The transformation impact of zooplankton is expected to be highly variable in coastal waters because copepod abundance changes by 3 orders of magnitude across seasons. Coastal waters are also characterised by relatively short food chains where each trophic level has a larger impact on the carbon flow than in areas with relatively longer chains, e.g. open water systems. Finally, coastal waters are shallow with a tight benthic-pelagic coupling, and aggregation of phytoplankton followed by rapid sinking results in a very efficient transport of high-quality organic matter to the benthos. Transit time for organic matter to reach the bottom is short, which reduces the degradation of FAs by factors other than zooplankton feeding.

Since mesozooplankton is the primary converter of low-energy phytoplankton sugars into high-energy lipids, we hypothesised that it is also a significant transformer of the FA profile of seston exported to the benthos. We expected that the FA content of sedimenting matter will be different depending on the activity of zooplankton and the seasonal changes in phytoplankton assemblages, both of which might affect the transformation. The vital rates of copepods (grazing, growth) set an upper limit for the impact they might have as transformers. Hence, by comparing the changes in FA content between seston and sediment traps, we may quantify the contribution of copepods to the pelagic processing of photosynthetically fixed carbon. To this end, we investigated the activity of copepods, their FA composition and the quantity and quality of sedimenting matter during 5 campaigns covering all 4 seasons at a coastal site on the west coast of Sweden.

\section{MATERIALS AND METHODS}

Sampling was carried out at a station near the entrance of the Gullmar Fjord $\left(58^{\circ} 15^{\prime} 2^{\prime \prime} \mathrm{N}, 11^{\circ} 26^{\prime} 2^{\prime \prime} \mathrm{E}\right.$, depth $43 \mathrm{~m}$ ) during 5 campaigns: 2 to 9 October 2006 (hereafter referred to as Oct 06); 22 to 29 January (Jan 07), 27 February to 14 March (Feb-Mar 07) and 6 to 13 July 2007 (Jul 07); and 14 to 21 March 2008 (Mar 08). We repeated the sampling scheme every second day, 4 to 6 times in total for each campaign. Basic data on temperature, salinity, in situ fluores- cence, chlorophyll, nutrients, phytoplankton and protist species composition are presented in a previous paper (Calliari \& Tiselius 2009).

Water was collected at the surface and at $5,10,15$, 20 and $30 \mathrm{~m}$ depth for particulate organic carbon (POC) and lipid analyses in seston with a Neil Brown CTD rosette system. In the laboratory, 400 to $1000 \mathrm{ml}$ for each analysis were filtered through pre-combusted GF/F filters and quickly deep frozen $\left(-80^{\circ} \mathrm{C}\right)$ until analyses. POC retained in filters was determined on a FISON Instruments NA 1500 NC Analyser (using acetinalide as the standard). For lipid analysis, filters were extracted in a chloroform:methanol mixture $(2: 1 \mathrm{vol} / \mathrm{vol})$.

Zooplankton was sampled with a $90 \mu \mathrm{m}$ WP-2 hauled vertically from $20 \mathrm{~m}$ depth to the surface. Samples were preserved with buffered formaldehyde ( $4 \%$ final concentration), and organisms were identified and counted under a dissecting microscope. Biomass was estimated from length measurements using length-weight regressions taken from the literature (Mauchline 1998, Rose et al. 2004).

Herbivorous ingestion rate for mesozooplankton was estimated from gut fluorescence (Mackas \& Bohrer 1976) as described in detail by Calliari \& Tiselius (2009). Briefly, animals were collected at night by gentle tows of a $250 \mu \mathrm{m}$ mesh net, instantly frozen, and in the laboratory, adults or C5 (copepods) were picked under dim light, extracted in 96\% ethanol and gut pigment content measured on a Turner Designs AU-10 fluorometer. Temperaturecorrected gut evacuation rates were used to estimate ingestion (Dam \& Peterson 1988). Egg and pellet production rates were estimated from bottle incubations at in situ temperature and food conditions as described by Calliari \& Tiselius (2009). Subsamples of eggs and pellets were measured (eggs: diameter, pellets: length and width), and pellets were converted to carbon by regressions for the Thalassiosira weissflogii diet in Urban-Rich et al. (1998).

Sedimenting pellets, pigments, POC and lipids were estimated from duplicate sediment traps at 15 and $30 \mathrm{~m}$ depth following Vargas et al. (2002). Traps were $60 \mathrm{~cm}$ long and $8 \mathrm{~cm}$ diameter cylinders moored at the sampling station (43 m depth). Traps were deployed on the first sampling day of each campaign, and every second day for $8 \mathrm{~d}$, the content of the traps (water and sedimented material) was collected in clean buckets and brought to the laboratory. Deployment time was $48 \mathrm{~h}$ with occasional shorter $(24 \mathrm{~h})$ and longer (72 to $96 \mathrm{~h}$ ) times depending on weather conditions. For POC and lipid analyses, between 50 and $350 \mathrm{ml}$ were filtered through pre-combusted GF/F 
filters, and further processing proceeded as described above. We then filtered 50 to $100 \mathrm{ml}$ of water on GF/F filters, extracted the pigments (chlorophyll and phaeopigments) in $96 \%$ ethanol in the dark at $4^{\circ} \mathrm{C}$, and after $24 \mathrm{~h}$, read the fluorescence as described above for the copepods. Sub-samples (10 to $50 \mathrm{ml}$ ) were taken for enumeration of pellets and size measurement. Pellet volumes were converted to carbon as described above.

For FA analyses in zooplankton, samples were collected by gentle tows of a $250 \mu \mathrm{m}$ mesh net, the catch diluted in temperature-insulated 201 buckets and transported to the laboratory. Less than $1 \mathrm{~h}$ after capture, samples were collected by sieving aliquots of the diluted sample with live animals onto several small pieces of plankton gauze, and quickly frozen at $-80^{\circ} \mathrm{C}$ until extraction. For extraction, samples were thawed in seawater in Petri dishes and kept at a temperature close to $0^{\circ} \mathrm{C}$ while picking individuals of target species, which were placed in vials containing a chloroform:methanol mixture $(2: 1 \mathrm{vol} / \mathrm{vol})$. The number of individuals per replicate varied according to species size, and was typically between 80 and 100 for smaller copepods and between 10 and 25 for Calanus helgolandicus.

The FA composition of seston, copepods and trap material was determined by extraction of the lipids by a chloroform:methanol mixture $(2: 1 \mathrm{vol} / \mathrm{vol})$ followed by trans-esterification of the lipids by acetyl chloride in methanol. The FA methyl esters were analysed by gas chromatography-mass spectrometry (GC-MS). Before the extraction started, $1.84 \mathrm{ng}$ internal standard solution of tricosanoic acid methyl ester (C23:0) in methanol was added to each vial. The vials were sonicated at $0^{\circ} \mathrm{C}$ for $2 \mathrm{~h}$, followed by evaporation of the solvent at $60^{\circ} \mathrm{C}$ under a flow of nitrogen. Reagent solution $(1 \mathrm{ml})$ composed of a mixture of toluene, methanol and acetyl chloride (40:50:10) was added, and the vials were heated for $2 \mathrm{~h}$ at $90^{\circ} \mathrm{C}$. Aqueous $\mathrm{NaHCO}_{3}(5 \%$ by weight, $1 \mathrm{ml})$ was added to the vials, and after vigorous shaking, the upper layer containing the FA methyl esters was removed. The water phase was extracted twice with heptane $(1 \mathrm{ml})$, and the combined organic layers were collected and evaporated at $60^{\circ} \mathrm{C}$ under a gentle stream of nitrogen. Finally, the methyl esters were resuspended in chloroform $(0.5 \mathrm{ml})$, and an aliquot of the sample $(5 \mu \mathrm{l})$ was analysed by GC-MS. The GC-MS instrument was composed of an Agilent 6890 series gas chromatograph equipped with a programmable temperature vaporisation (PTV) inlet and an Agilent 5973 mass selective detector. The column was a 60 m Agilent DB23 with an inner diameter of
$250 \mu \mathrm{m}$ and a film thickness of $0.3 \mu \mathrm{m}$. The carrier gas was helium at a constant flow rate of $1 \mathrm{ml} \mathrm{min}^{-1}$. The oven temperature program was initially at $60^{\circ} \mathrm{C}$ with a temperature ramp of $24.6^{\circ} \mathrm{C} \mathrm{min}^{-1}$ until $200^{\circ} \mathrm{C}$, which was maintained for $10 \mathrm{~min}$ followed by a second temperature ramp of $5^{\circ} \mathrm{C} \mathrm{min}{ }^{-1}$ until $250^{\circ} \mathrm{C}$, which was kept for $3 \mathrm{~min}$. The mass spectrometer was run in selective ion monitoring mode (SIM) by application of the masses $\mathrm{m} / \mathrm{z}=55,74,79$ and 81 . The PTV inlet was operated in split-less mode and with the evaporation program going from 60 to $300^{\circ} \mathrm{C}$ with a temperature ramp of $720^{\circ} \mathrm{C} \mathrm{min}^{-1}$ and kept for 2 min. It should be noted that the F.A.M.E. Mix C4C24 (SUPELCO 18919-1AMP) external standard for the analysis did not include some potentially important PUFAs (e.g. C16, C18:4), but we did detect the major FAs in seston and zooplankton.

\section{Statistical analysis}

Comparisons between campaigns for herbivorous grazing, pellet production, egg production and total FA concentration were made by single factor analysis of variance (ANOVA) followed by Student-NewmanKeuls (SNK) post hoc tests. Sedimentation rates were analysed separately at 15 and $30 \mathrm{~m}$, since 2 -factor ANOVAs showed consistently higher values at $30 \mathrm{~m}$. Linear regressions were used to relate copepod egg production to lipid content and for comparisons between seston and trap FA composition and PUFA concentrations. Temporal variability of sedimentation was evaluated by comparing coefficients of variation $(\mathrm{CV}=\mathrm{SD} /$ mean $\times 100)$. Variables were checked for heteroscedasticity by Levene's test and $\log (x+1)$ transformed if necessary. If this transformation did not result in homogeneous variances, a KruskalWallis test was used. FAs were grouped into SAFAs, MUFAs and PUFAs following Brett \& Müller-Navarra (1997). Fractions of PUFA, docosahexaenoic acid (22:6(n-3), DHA) and eicosapentaenoic acid (20:5(n-3), EPA) were arcsine transformed before analysis. Significance was considered at $\mathrm{p}<0.05$, and all analyses were performed in SPSS (v.13) for Macintosh.

\section{RESULTS}

The protist biomass ranged from 2 to $54 \mathrm{mg} \mathrm{C} \mathrm{m}^{-3}$, and the autumn showed a dominance of dinoflagellates (mainly Ceratium spp.), while diatoms were important autotrophs during the rest of the year (Fig. 1A). In Jul 07, the diatoms were dominated by the large 

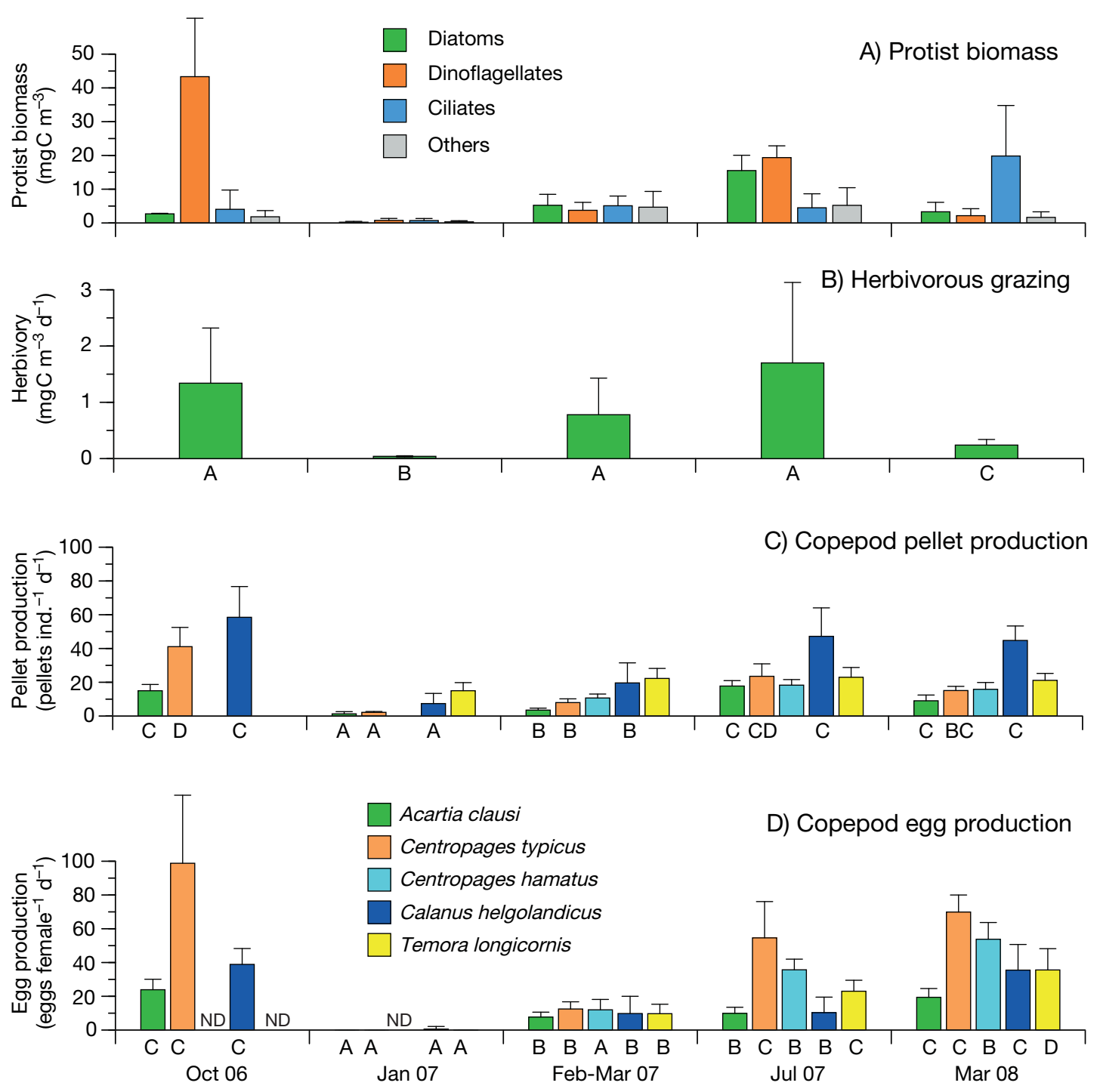

Fig. 1. (A) Biomass $\left(\mathrm{mg} \mathrm{C} \mathrm{m}^{-3}\right)$ of major phytoplankton and protist groups. 'Others' include small cryptophytes and raphido-

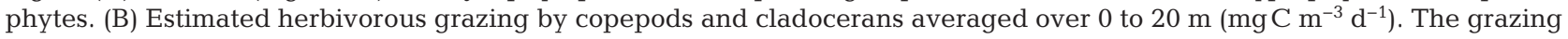
is based on gut fluorescence measured at night in animals collected at 0 and $5 \mathrm{~m}$ depth and then multiplied by the biomass (Table 1), $\mathrm{n}=4$ to 8 . (C) Copepod pellet production (pellets ind. ${ }^{-1} \mathrm{~d}^{-1}$ ) and (D) copepod egg production (eggs female $\mathrm{d}^{-1}$ ), estimated from bottle incubations ( $\mathrm{n}=1$ to $4 \mathrm{~d}^{-1}, 4$ to $8 \mathrm{~d}$ per campaign). (b-d) Different letters below bars indicate that samples are significantly different $(\mathrm{p}<0.05$, SNK post hoc test). If ANOVA results were non-significant, no letters are shown.

Data: mean + SD. ND: no data

Proboscia alata and the small Pseudonitzschia delicatissima, and dinoflagellates were generally $<10 \mu \mathrm{m}$. Ciliates dominated after the spring bloom in Mar 08. The mesozooplankton biomass ranged from 0.5 to $10 \mathrm{mg} \mathrm{C} \mathrm{m}^{-3}$, with the lowest values in Jan 07 and the highest in Jul 07 (Table 1). Copepods dominated, but cladocerans and appendicularians were important at times. Oithona spp. were always important, and calanoids were dominated by Acartia clausi with Calanus helgolandicus and Centropages typicus important in Oct 06, Temora longicornis and Pseudo- calanus sp. in Jan 07, Feb-Mar 07 and Mar 08 and Paracalanus parvus in Jul 07. The cladoceran Penilia avirostris was very abundant in Oct 06, and Oikopleura dioica was common in Jul 07.

The zooplankton grazing estimated from gut fluorescence was high in Oct 06, Feb-Mar 07, and Jul 07, ranging from 0.8 to $1.7 \mathrm{mg} \mathrm{C} \mathrm{m}^{-3} \mathrm{~d}^{-1}$ (Fig. 1B). Significantly lower values were recorded in Mar 08 and the lowest in Jan 07. The pellet production reflected the grazing estimate with the highest values in Oct 06 and Jul 07 (Fig. 1C). Calanus helgolandicus produced 
Table 1. Mean (SD) biomass $\left(\mu \mathrm{gC} \mathrm{m}^{-3}\right)$ of zooplankton $>90 \mu \mathrm{m}_{i} \mathrm{n}=4$, except Feb-Mar 07 where $\mathrm{n}=6$. nd: not detected

\begin{tabular}{|lccccc|}
\hline & Oct 06 & Jan 07 & Feb-Mar 07 & Jul 07 & Mar 08 \\
\hline Calanus helgolandicus & $300(511)$ & $75(11)$ & $32(35)$ & $709(363)$ & $241(245)$ \\
Acartia clausi & $161(96)$ & $117(44)$ & $194(72)$ & $2431(1831)$ & $270(45)$ \\
Centropages sp. & $255(222)$ & $6.3(7.4)$ & $39(32)$ & $711(240)$ & $73(61)$ \\
Pseudocalanus sp. & $16(17)$ & $67(13)$ & $164(147)$ & $310(290)$ & $397(204)$ \\
Paracalanus parvus & $53(31)$ & $14(18)$ & $129(164)$ & $2826(1569)$ & $149(65)$ \\
Temora longicornis & $0.6(0.5)$ & $67(95)$ & $453(405)$ & $10(21)$ & $542(283)$ \\
Copepod nauplii & $198(208)$ & $29(16)$ & $205(58)$ & $1138(395)$ & $1148(869)$ \\
Oithona spp. & $446(215)$ & $14(3)$ & $37(15)$ & $1417(437)$ & $125(57)$ \\
Corycaeus sp. & $60(22)$ & $60(22)$ & nd & nd & $5.1(3.7)$ \\
Oncaea sp. & nd & $1.0(0.8)$ & $1.1(1.5)$ & $1.4(1.6)$ & $3.8(6.8)$ \\
Penilia avirostris & $815(390)$ & nd & nd & nd & nd \\
Podon sp. & nd & nd & nd & $0.3(0.4)$ & $3.9(6.0)$ \\
Evadne nordmanni & nd & nd & nd & $2.7(4.0)$ & $9.4(5.7)$ \\
Oikopleura dioica & $246(208)$ & nd & $4.9(6.6)$ & $661(415)$ & $32(23)$ \\
Total & 2551 & 450 & 1259 & 10219 & 2999 \\
\hline
\end{tabular}

the highest number of pellets (mean \pm SD): $59 \pm$ 18 pellets ind. ${ }^{-1} \mathrm{~d}^{-1}$ in Oct 06, $47 \pm 17$ in Jul 07 and $45 \pm 9$ in Mar 08. Acartia clausi and Centropages typicus showed the same seasonal pattern, but with lower values. Temora longicornis and Centropages hamatus showed no significant seasonal difference in pellet production. The copepod egg production was highest in Oct 06 (C. typicus, C. helgolandicus, A. clausi) and Mar 08 ( $T$. longicornis, $C$. hamatus, Fig. 1D). C. typicus was most fecund (99 \pm 40 eggs female $\left.{ }^{-1} \mathrm{~d}^{-1}\right)$ followed by $C$. hamatus $(54 \pm 10)$ and $C$. helgolandicus $(39 \pm 9)$. The 2 campaigns in Jan 07 and Feb-Mar 07 were significantly lower in egg production than the Mar 08 sampling, similar to the pattern for pellet production.

Total carbon sedimentation estimated from POC varied between 220 and $590 \mathrm{mg} \mathrm{C} \mathrm{m}^{-2} \mathrm{~d}^{-1}$ at $15 \mathrm{~m}$ and significantly more (650 to $1500 \mathrm{mg} \mathrm{C} \mathrm{m}^{-2} \mathrm{~d}^{-1}$ ) at $30 \mathrm{~m}$ (Fig. 2). The difference between depths was significant, but there was no difference in POC flux between sampling campaigns at either depth. The pigment sedimentation ranged from 0.8 to $3.5 \mathrm{mg}$ pigment $\mathrm{m}^{-2} \mathrm{~d}^{-1}$ at the $15 \mathrm{~m}$ trap and significantly more (1.7 to $4.9 \mathrm{mg} \mathrm{m}^{-2} \mathrm{~d}^{-1}$ ) at the $30 \mathrm{~m}$ trap (Fig. 2). This sedimentation rate corresponds to a relatively low sinking speed of 1 to $3 \mathrm{~m}$ $\mathrm{d}^{-1}$ at $15 \mathrm{~m}$ and twice that at $30 \mathrm{~m}$. There was a seasonal difference at $15 \mathrm{~m}$, where Oct 06, Jul 07 and Mar 08 were significantly higher than Jan 07 and FebMar 07. Pellet carbon flux also varied with season (Kruskal-Wallis test, $H=11.4, \mathrm{df}=4, \mathrm{p}=0.023$ and $H=$ $11.9, \mathrm{df}=4, \mathrm{p}=0.018$, for 15 and $30 \mathrm{~m}$, respectively). Highest values were recorded in Jul 07, slightly lower in Oct 06 and Mar 08 and lowest in January and FebMar 07 (Fig. 2). The seasonal difference at $15 \mathrm{~m}$ was

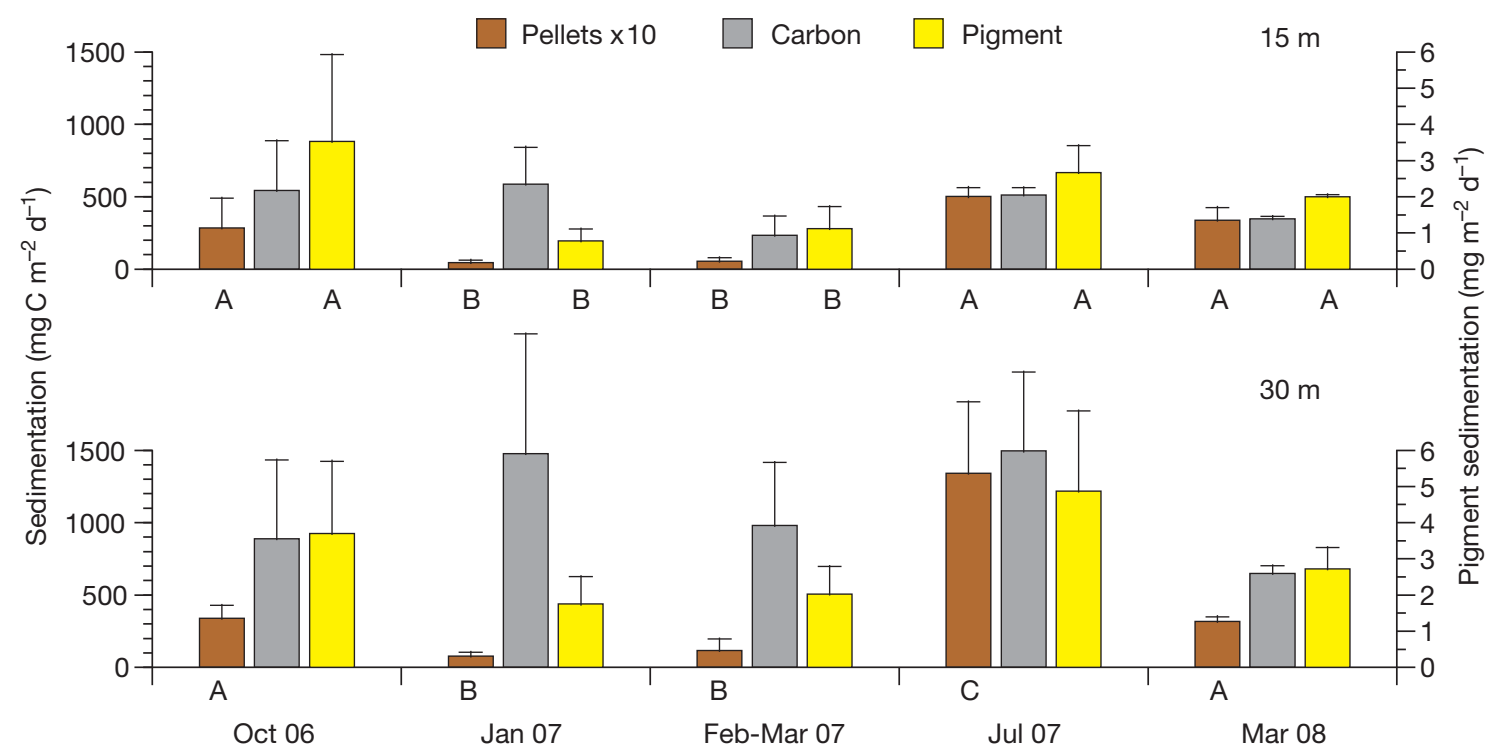

Fig. 2. Sedimentation rates of copepod faecal pellet carbon (multiplied by 10) and particulate organic carbon (both on left axis) and pigment sedimentation rate (right axis) measured in sediment traps at 15 and $30 \mathrm{~m}$ depth. Faecal pellet carbon estimated from volume of pellets. Different letters below bars indicate that samples are significantly different $(p<0.05$, SNK post hoc test). If ANOVA results were non-significant, no letters are shown. Data: mean + SD 


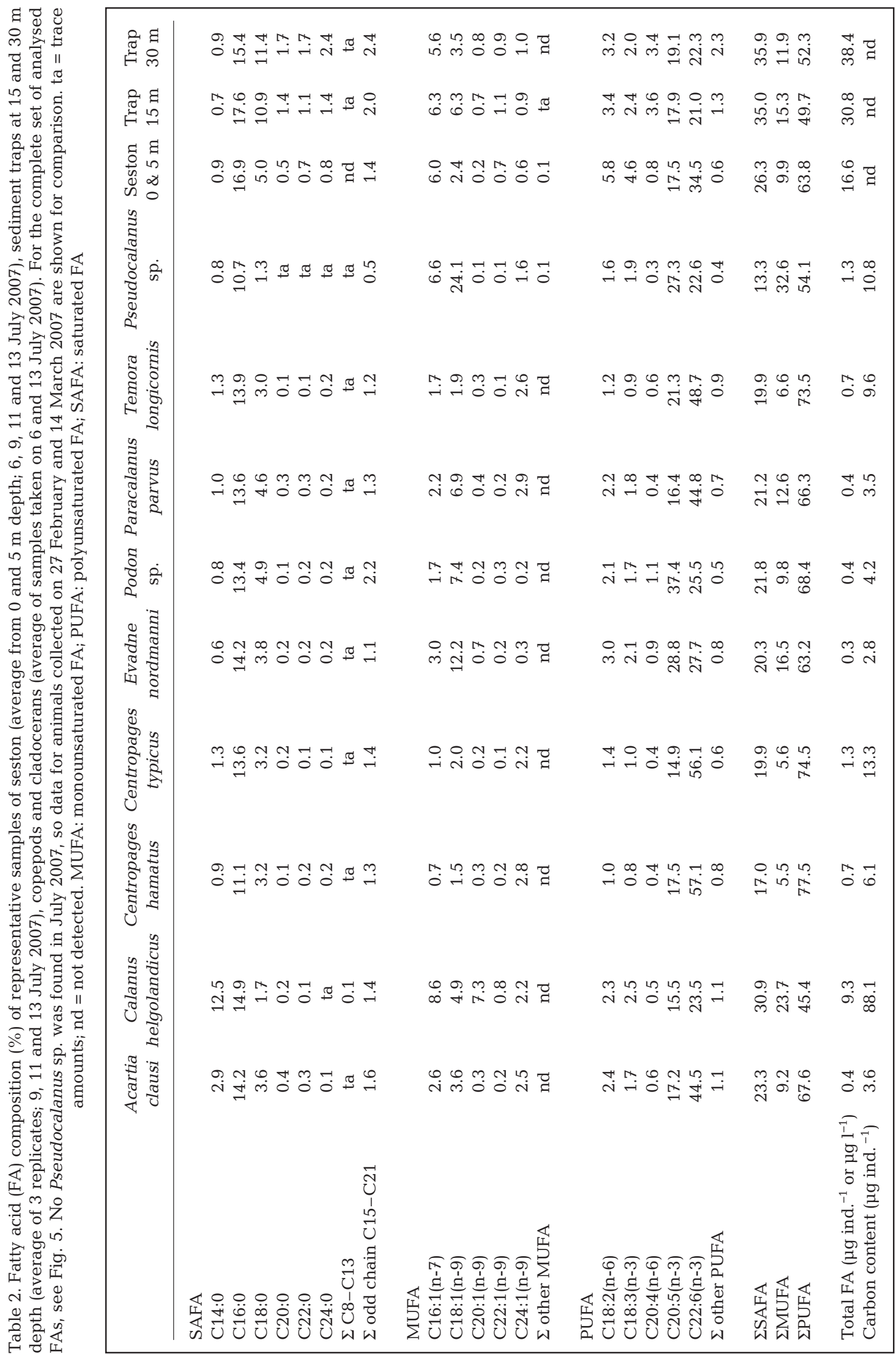



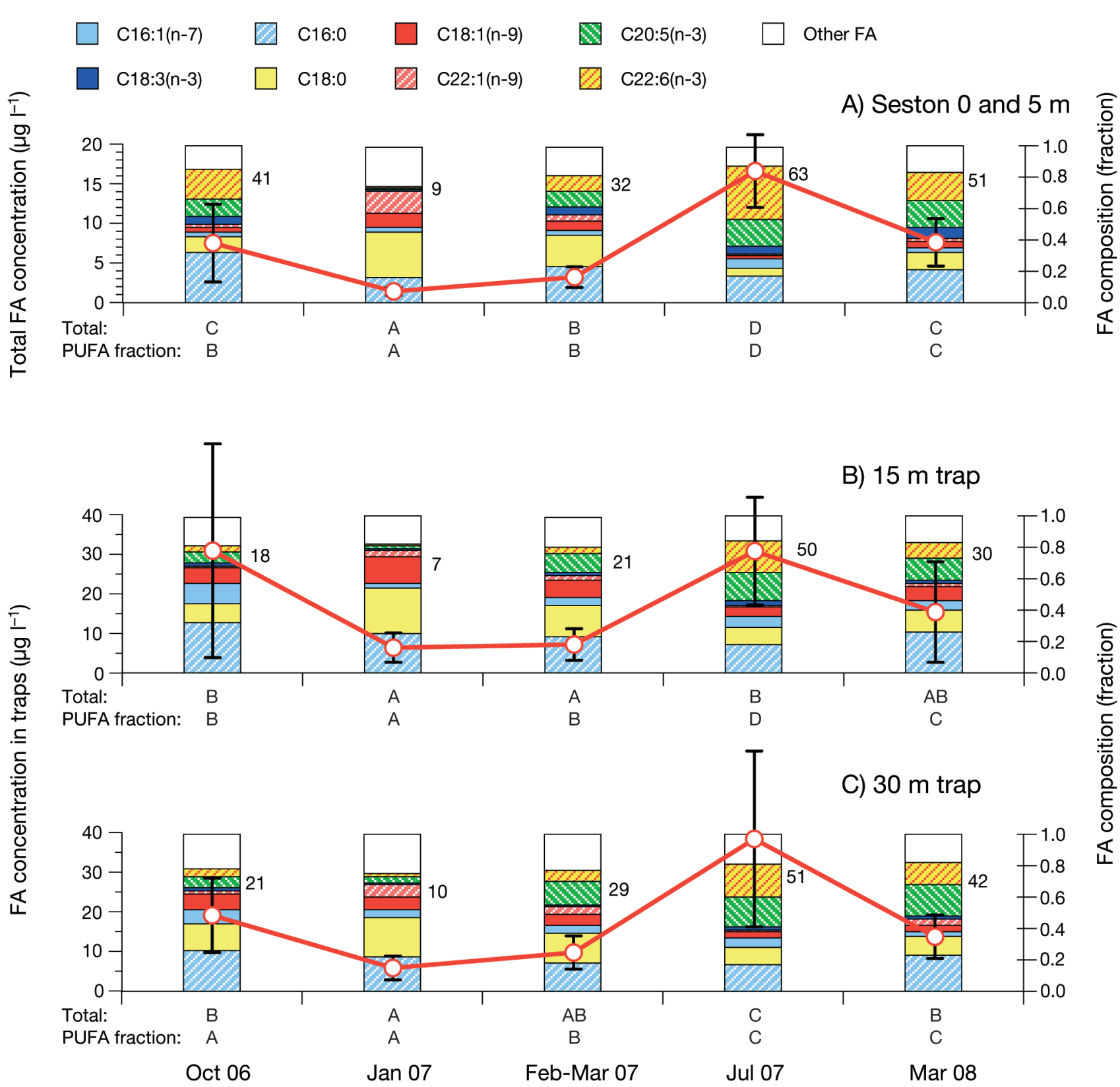

Fig. 3. Fatty acid (FA) concentration ( $\mu \mathrm{g} \mathrm{l}^{-1}, \pm \mathrm{SD}$; white dots and red line, left $y$-axis) and composition (fraction of total concentration of all FAs detected; stacked columns, right $y$-axis) in (A) seston (average 0 and $5 \mathrm{~m}$ ), and in sediment traps at (B) $15 \mathrm{~m}$ and (C) $30 \mathrm{~m}$ depth. Estimates from sediment traps are concentration inside the trap, which had a volume of 2.61 . Traps were deployed for 24 to $96 \mathrm{~h}$. Different letters below bars indicate that samples are significantly different ( $p<0.05$, SNK post hoc test) for total FA concentration (top row) and the fraction of polyunsaturated FAs (PUFAs, bottom row). The PUFA fraction values (\%) are shown next to each column

the same as for the pigment, while at $30 \mathrm{~m}$, the value for Jul 07 was significantly higher than the rest.

A complete analysis of FAs for Jul 07 is shown in Table 2, but for presentation of temporal trends and differences between seston, traps and zooplankton, the 8 most important FAs are shown in Figs. 3 \& 4 . FA concentrations in seston ranged from 2 to $18 \mu \mathrm{g} \mathrm{l}^{-1}$ and reflected the total abundance of protists in the water, with significant differences between all campaigns except Oct 06 and Mar 08 (Fig. 3A). Lowest values occurred in Jan 07 and Feb-Mar 07, highest in Jul 07, and intermediate in Mar 08 and Oct 06. C16 and C18 SAFAs and MUFAs dominated the seston with concentrations of 0.5 to $3.8 \mu \mathrm{g} \mathrm{l}^{-1}$, except in Jul 07 when 


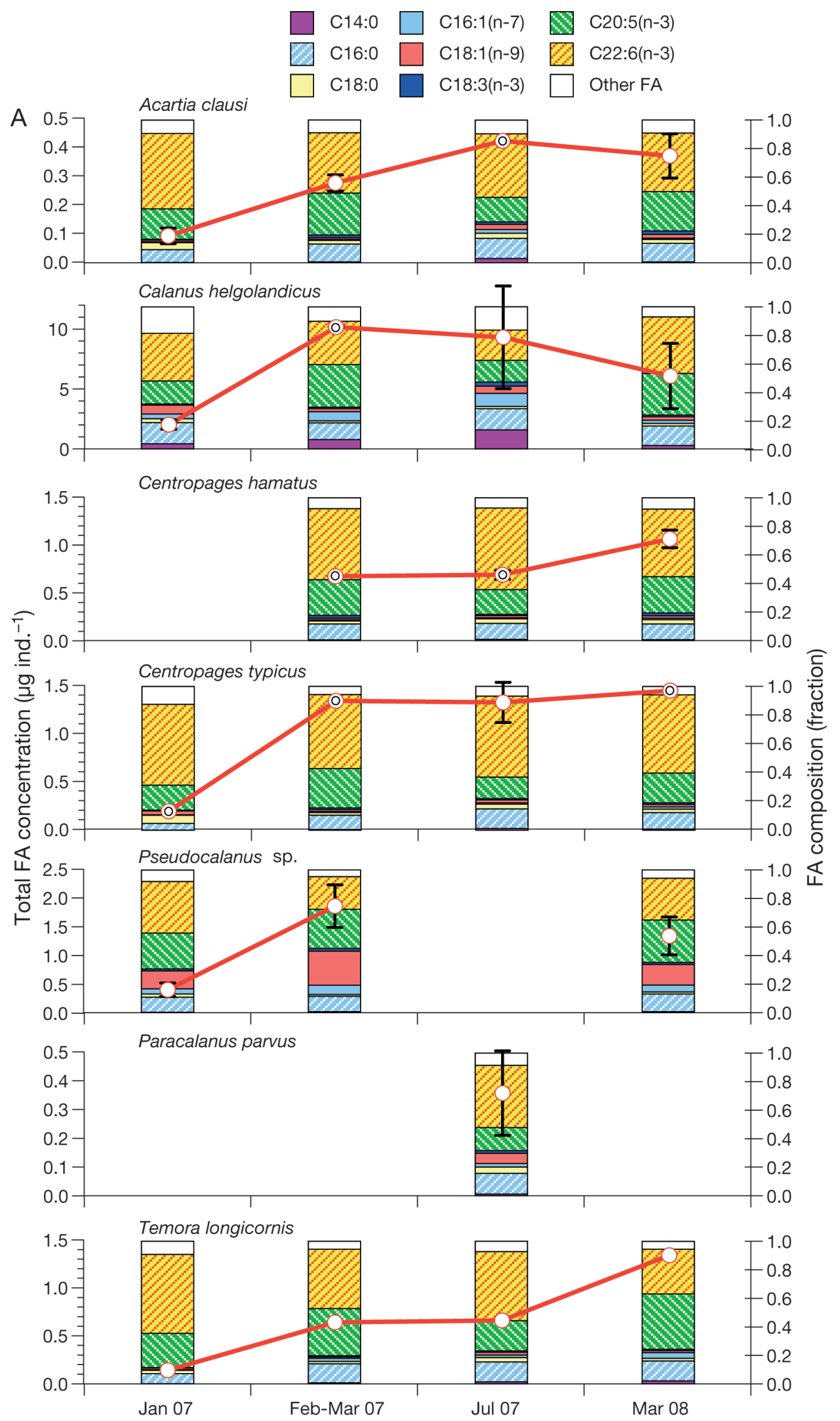

Fig. 4. (A) Adult copepod and (B) juvenile and cladoceran fatty acid (FA) concentration ( $\mu \mathrm{g}$ ind. ${ }^{-1}, \pm \mathrm{SD}_{i}$ white dots and red line, left $y$-axis) and composition (fraction; stacked columns, right $y$-axis). FAs shown always contributed $>90 \%$ of the total FAs in the animals. Each value is the average of 2 samples, one at the start and end of each campaign. Cases where $\mathrm{n}=1$ are indicated by a black circle inside the symbols 


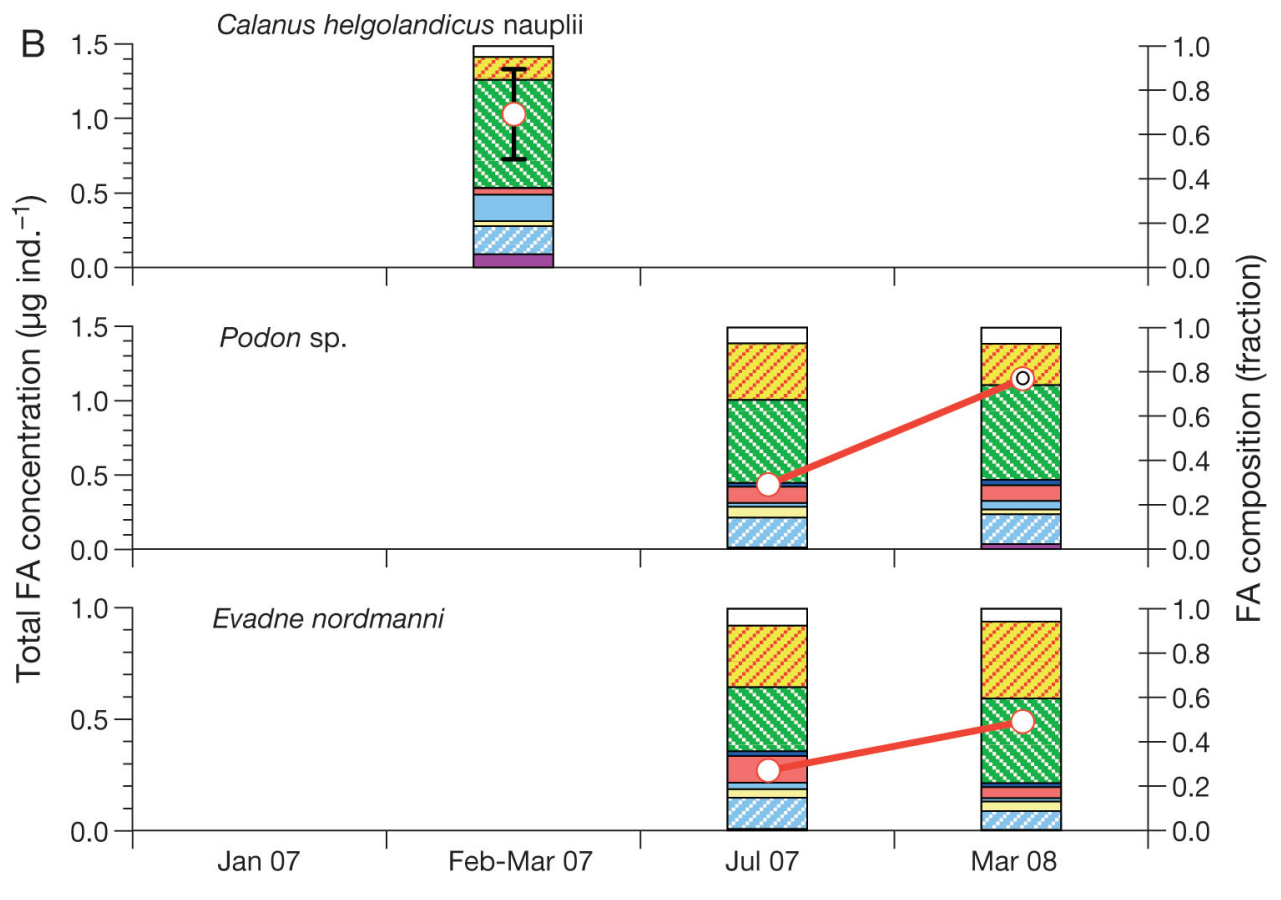

Fig. 4 (continued)

PUFAs were higher $\left(10.5 \mu \mathrm{g}^{-1}\right)$. Whenever total FA content was high $\left(>5 \mathrm{gg} \mathrm{l}^{-1}\right)$, PUFAs were important, contributing 41 to $63 \%$ of the concentration. EPA and DHA were the dominant PUFAs, with DHA at twice the concentration of EPA in Oct 06 and Jul 07, but otherwise similar. The fraction PUFA/total FA (Fig. 3A) was significantly different between campaigns, with the highest values in Jul 07 and lowest in Jan 07.

The sediment traps had a modified FA profile compared to the seston. The total amount followed seston concentrations except in Oct 06, when the sedimentation was proportionally higher (Fig. 3B,C). MUFAs were particularly increased, and there were taxonspecific signals such as elevated C16:1 indicating preferential sedimentation of diatoms. The most important difference between traps and seston was the decrease in PUFAs (Fig. 5). Overall, the sedimented material was reduced in PUFAs by 11 to $23 \%$ compared to seston, and this difference was significant for Oct 06 and Jul 07 (both $\mathrm{p}<0.001$ ) with a tendency for Feb-Mar $07(p=0.077)$ and Mar $08(p=0.063)$, and there was no difference in Jan $07(p=0.21)$. The reason for the reduction was entirely attributed to reductions in DHA, which was significantly reduced in traps in Oct 06, Feb-Mar 07 and Jul 07. In contrast EPA was never significantly reduced.

The FA profile of the copepods and cladocerans was radically different from their food (Fig. 4). The total amount of FA in adult females varied between species from the smallest Acartia clausi and Para- calanus parvus with 0.1 to $0.5 \mu \mathrm{g}$ ind. ${ }^{-1}$ to the largest Calanus helgolandicus with 2 to $10 \mu \mathrm{g}$ ind. ${ }^{-1}$. Centropages hamatus contained about $1 \mu \mathrm{g}$ ind..$^{-1}$ and its larger congener C. typicus contained up to $1.5 \mu \mathrm{g}$ ind. ${ }^{-1}$. Pseudocalanus sp. and Temora longicornis reached 1.5 to $2.0 \mu \mathrm{g}$ ind. ${ }^{-1}$. Total FA content was lowest in Jan 07 for all species, but lack of replication (only 2 samples per campaign) prevented statistical analysis.

The FA composition of the copepods remained remarkably stable despite changes in total amount. PUFAs contributed 75 to $90 \%$ of the FA in all species, except Pseudocalanus sp. that showed high amounts of C18:1 (12 to $24 \%$ ) and Calanus helgolandicus that contained C16:1(n-7) (2 to $9 \%$ ) and C14:0 (2 to 13\%). DHA was the most important PUFA, but EPA reached similar levels in spring. The FA composition of the nauplii of $C$. helgolandicus was dominated by EPA, but resembled the composition of the parents in also containing C16:1(n-7) and C14:0 (Fig. 4B). The cladocerans Podon sp. and Evadne nordmanni contained more EPA than DHA, and PUFAs contributed 60 to $80 \%$ of their FA content. The highest total content occurred after the spring bloom in Mar 08 (Fig. 4B).

\section{DISCUSSION}

The FA composition in plankton is an important factor for the productivity of the ecosystem. In particular, 
Fig. 5. Difference in fatty acid (FA) composition between seston ( 0 and $5 \mathrm{~m}$ depth) and sediment traps at $15 \mathrm{~m}$. All FAs included in the standard are shown, except the C8-C13 saturated FAs (SAFAs), which were only found in trace concentrations. Horizontal bars indicate the percent difference between seston and traps estimated as the difference between stacked bars in Fig. 3A,B. A positive number (bars to the right) indicates a higher fraction in seston than in the trap

the PUFA content has received attention as a limiting factor for growth and reproduction in cladocerans (Brett \& Müller-Navarra 1997) and copepods (e.g. Anderson \& Pond 2000, Jónasdóttir et al. 2002, Dutz \& Peters 2008, Mayor et al. 2011). The plankton of the Gullmar Fjord was found to contain remarkably high levels of PUFA, comparable to the western English Channel (Pond et al. 1996), the Trondheim fjord (Evjemo et al. 2008) and the central Chilean upwelling (Vargas et al. 2006), but much higher than levels in the North Sea (Kreibich et al. 2008), the Balsfjorden (Hamm \& Rousseau 2003) and the eastern English Channel (Cotonnec et al. 2001). Thus, even though our study did not include major phytoplankton blooms, the seston was rich in PUFAs, and this composition was also reflected in the FA content of the copepods.

The FA profile in copepods was different from seston irrespective of total FA levels in their biomass. This difference was more pronounced in our study than previously observed by Cotonnec et al. (2001), Hazzard \& Kleppel (2003), Evjemo et al. (2008) and in freshwater zooplankton by Persson \& Vrede (2006). Compared to seston, copepods accumulated specific PUFAs like the essential EPA and DHA (between 3 and 17 times, normalised to copepod body carbon). An obvious reason is that seston in the Gullmar Fjord contained more PUFA. A further sign of the high PUFA content in the fjord is the high level of DHA and EPA in overwintering copepods. Extremely low seston biomass in Jan 07, but rather constant PUFA levels in the copepods at that time, implies that they must have had access to higher levels of PUFA during the period prior to Jan 07 .

The high PUFA content of the copepods mostly reflects the composition of their lipid membranes, and it can be expected that this composition is relatively stable for each species. All copepods obtain their PUFAs from the diet, and some of the larger, arctic copepods can elongate and desaturate FAs (Dalsgaard et al. 2003). Storage lipids were found in Pseudocalanus sp. and Calanus helgolandicus, but not in the other species.

Two groups of copepods could be distinguished based on their PUFA content, mainly EPA and DHA

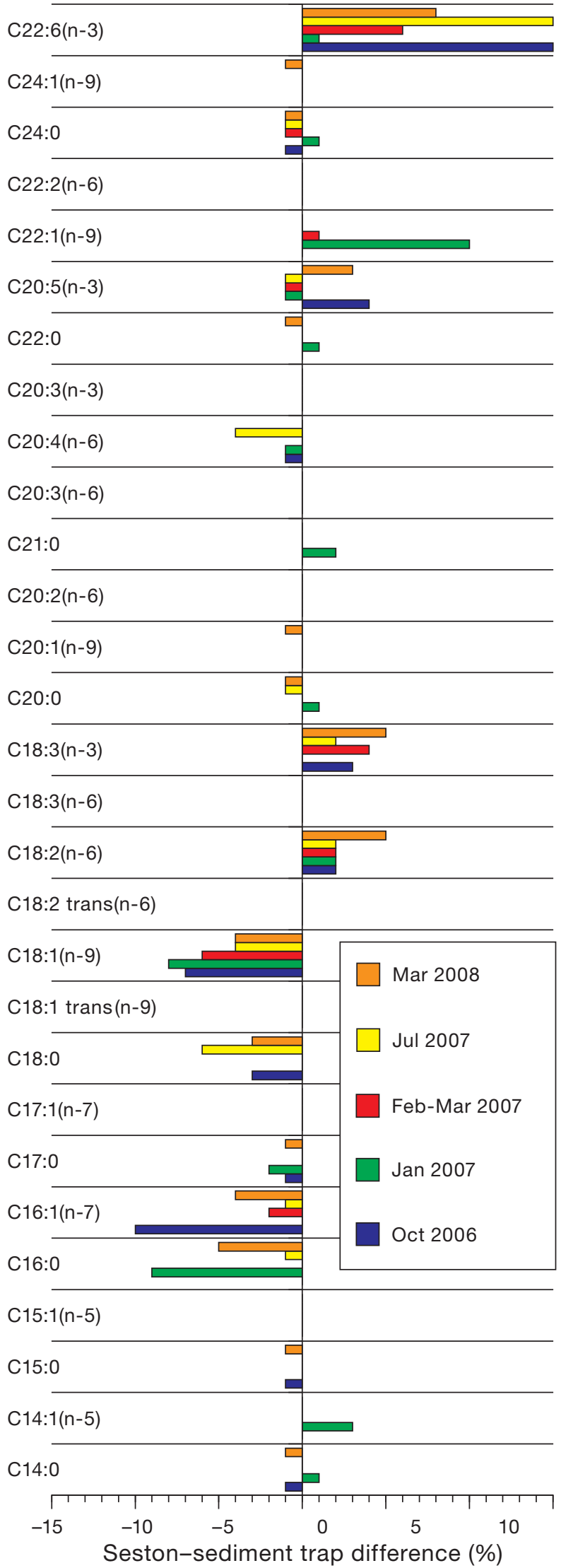



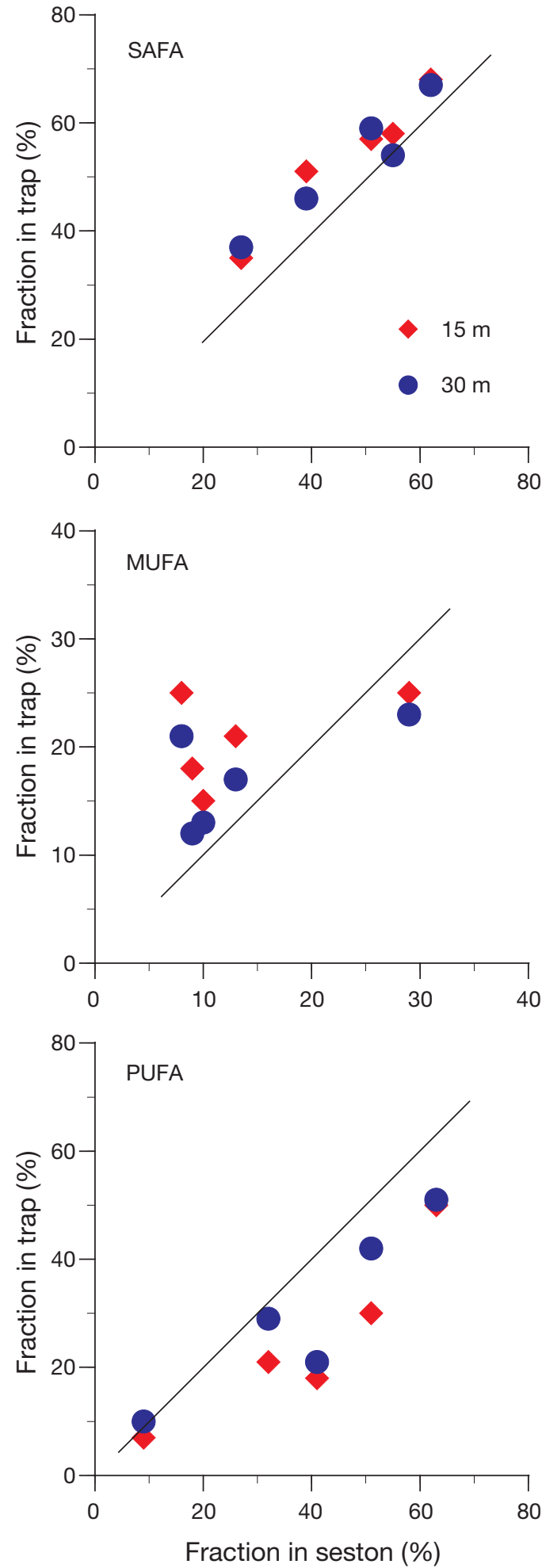

Fig. 6. Relative contribution of saturated, monounsaturated and polyunsaturated fatty acids (SAFA, MUFA and PUFA, \%) in sediment traps at 15 and $30 \mathrm{~m}$ versus the contribution in seston ( 0 and $5 \mathrm{~m}$ depth). Line indicates a 1:1 relationship, i.e. that the contribution of a given group of FA is the same in seston and traps. Values above the line indicate that there is a higher fraction of a given group of FAs in traps than in seston
(Fig. 4). The most pronounced PUFA accumulation was found in Centropages typicus, C. hamatus, Acartia clausi and Temora longicornis. The FA composition was highly stable despite changes of an order of magnitude in total FA content. The coefficient of variation was only 2 to $6 \%$ for the fraction of PUFA over all seasons and also displayed the smallest fraction of MUFAs $(5$ to $7 \%)$. The high PUFA content suggests predation on ciliates (Mar 08) or dinoflagellates (Jul 07) with high PUFA content (Klein Breteler et al. 1999) or other animal prey. While the fraction of PUFA remained constant in this group, the total amount of FA in an animal varied by a factor of 2 to 10 . This extreme variation in PUFA is not coupled to storage lipids or changes in lipid contents of cell membranes, but it could be related to gonad growth. In fact, there was a linear relationship between total FA content of the copepods and their specific egg production $(p=0.021$, $\mathrm{R}^{2}=0.14, \mathrm{n}=39$; data not shown), but the regression only explained $14 \%$ of the variation. Hence, several other factors (e.g. food quality other than FA composition, total ingestion) will also affect egg production.

The second group consisted of Calanus helgolandicus, Pseudocalanus sp. and Paracalanus parvus, for which the contribution of PUFAs was lower and more variable. The diatom marker C16:1(n-7) and the SAFA C:14 (4-13\%) were found in C. helgolandicus, which has a greater ability to store lipids than the previously mentioned copepods. The presence of diatom markers also supports a herbivorous diet (Kattner \& Krause 1989). C. helgolandicus showed the largest variation in PUFA content and a closer resemblance to the seston FA, which indicates less selective feeding. Pseudocalanus sp. had elevated amounts of 18:1(n-9), and it was the only species in the study containing significant amounts of this MUFA. Seston contained 18:1(n-9) mainly during the spring, and small amounts in Jan 07. 18:1(n-9) is characteristic of prymnesiophytes and cryptophytes (Dalsgaard et al. 2003), which were found on all occasions. It is likely that Pseudocalanus sp. had accumulated 18:1(n-9) from small flagellates that were not ingested by other species. Cotonnec et al. (2001) also found elevated amounts of 18:1(n-9) in P. elongates and attributed this composition to selective feeding on Phaeocystis sp.

Storage lipids rich in SAFA and MUFA were found in the second group, but even during periods of high food supply and high FA content (Fig. 4), PUFA was still the dominant group of FA. This composition contrasts strongly with large arctic species where the storage lipids dominate the FA profile (Sargent \& Falk-Petersen 1988). 
The main differences in FA composition between seston ( 0 and $5 \mathrm{~m}$ depth) and traps at 15 and $30 \mathrm{~m}$ depth were that SAFAs and MUFAs always (with 1 exception) contributed more to total FA content in sediment traps than in seston; i.e. the PUFA fraction of FA was significantly reduced in the traps (Fig. 6). Symbols above the 1:1 line in the figure indicate a higher proportion in traps than in seston. On average $( \pm \mathrm{SD})$, this reduction was $17 \pm 6 \%$ and $11 \pm 7 \%$ at 15 and $30 \mathrm{~m}$, respectively, excluding the Jan 07 value when grazer biomass was very low. There was no significant difference between trap depths $(t$-test, $\mathrm{p}=$ 0.24). Similar results were reported by Claustre et al. (1992) by comparing the unsaturation index in seston and faecal pellets. The reduction is the result of biological activity in the water column and could partly be accounted for by the grazing and pellet production of the copepods and the cladocerans. Even though the demand for PUFAs in the zooplankton is difficult to estimate, it is clear from Fig. 4 that they selectively retain a high proportion of PUFAs, in particular EPA and DHA. Results discussed so far are consistent with a high recycling efficiency of essential PUFAs in the water column mediated by selectively feeding copepods.

POC flux was significantly higher at $30 \mathrm{~m}$ than at $15 \mathrm{~m}$, but there were no seasonal differences at either depth. The POC flux varied only by a factor of 2 and was lower than previous estimates from the Gullmar Fjord (Waite et al. 2005). Highest pigment flux at both depths was similar to estimates from the spring bloom in the fjord (Vargas et al. 2002), but the phytoplankton were far from bloom conditions in the fjord (Waite et al. 2005). Estimated sinking velocities were always higher at $30 \mathrm{~m}$ than at $15 \mathrm{~m}$, which is consistent with a gradual increase in particle or aggregate size with depth (e.g. Tiselius \& Kuylenstierna 1996). The relatively constant POC flux suggests that the sedimentation and the pelagic processes are decoupled even at this shallow coastal site. POC is to a large extent refractory, consisting of detritus, humic substances and other particles that are only partly incorporated into the pelagic food web. The slow and constant sedimentation observed in this study is therefore to be expected. The sedimenting POC (evaluated from the Jan 07 sampling) contained few PUFAs and mainly consisted of C16:0, C18:0 and C18:1. This FA composition is not optimal for benthic animals, which will likely get valuable PUFAs mainly during short events of increased algal sedimentation. The PUFA content in the seston is higher during blooms (e.g. Mayzaud et al. 1989) and also during summer in this study when phytoplankton domi- nated the suspended particulate material (July and October, Fig. 1A). Entry of PUFA into the food web in this situation is through the feeding copepods, and we suggest that the variation in pellet and pigment fluxes will affect the quality of food for the benthos.

Variation in vertical flux is coupled to the grazing activity of the copepods and to the direct sedimentation of phytoplankton blooms. Pellet flux is the strongest proxy for actively feeding zooplankton, and also showed the highest variability with a CV of $100 \%$ for the 5 campaigns analysed. This high variability means that the copepods respond fast to changes in food supply, which is reflected in variable pellet production. An important fraction of the sedimentation is not coupled to grazing, but comes from direct algal sinking. The variation for pigment sedimentation ( $\mathrm{CV}=49 \%$ ) was approximately half of that for pellets, which indicates that pigments from direct sedimentation and pellets are less variable than the grazing activity. The least variable flux estimate $(\mathrm{CV}$ $=33 \%$ ) was observed for POC, in line with a more constant sedimentation uncoupled to pelagic grazing activity or phytoplankton dynamics.

The sedimented material consists of carbon from different sources, and only part of the vertical flux is affected by zooplankton. Pellets contributed 5\% (range 1 to 10) and pigments contributed 15\% (range 5 to 26) of POC flux assuming a conservative carbon: pigment ratio of 40 (data from Fig. 3B,C). The POC flux to the sediment was quantitatively dominated by refractory material, but a significant fraction was dependent on biological activity, either through direct phytoplankton sedimentation, or grazing by zooplankton. Since no phytoplankton blooms occurred in our study, direct phytoplankton sedimentation is potentially underestimated.

A potential source of error in the estimation of sedimentation is the breakdown of FAs inside the traps. Bacterial breakdown of pellets and organic matter will occur during sinking and inside the traps, and may be detected as increases in odd-numbered FAs (Kaneda 1991). However, we observed only negligible amounts of odd-numbered FAs in the sediment traps $(<4 \%$ of total FA). The low fraction of odd-numbered FAs in our study is in accordance with other studies (Claustre et al. 1992, Budge et al. 2001), and bacterial breakdown in the traps can therefore be assumed to be low. PUFAs are labile molecules sensitive to autoxidation (Ding \& Sun 2005), but Ahlgren et al. (1997) concluded that autoxidation was not a problem even in long trap deployments ( 7 to $21 \mathrm{~d}$ ). The combination of low temperature and short trap deployment in our study should have fur- 
ther limited autoxidation. We thus conclude that differences between seston and trap FAs were caused by sedimentation of different fractions of the seston and by the grazing activity of zooplankton.

The addition of FA analysis to traditional measures of pigment or POC in vertical flux studies reveals important aspects of the functioning of this coastal ecosystem. First, it indicates the food quality of the sinking material. During summer (July), PUFAs comprise over $50 \%$ of the sedimenting FAs, while total FA sedimentation is 6 times higher than in January. In Jan 07, no PUFAs sank to the bottom, and the quality of the material as food for benthos was low. The FA information therefore suggests that benthos would benefit much more from the sedimenting matter in summer, despite a high vertical carbon flux in both seasons. Second, the activity of the copepods was reflected in an altered FA profile in the sedimented material. Even though copepod pellets accounted for a small fraction of the carbon sedimentation, their importance for the FA dynamics was higher.

In conclusion, the major part of the POC vertical flux has little nutritious value for the benthos. The flux is relatively constant and contains limited amounts of PUFA, indicating a refractory character and a low food quality for the benthos. The fraction of primary production that is channelled through the copepods apparently undergoes substantial transformation; PUFAs are retained by the zooplankton and therefore reduced in the sedimenting material. However, PUFAs will also reach the benthos through export of material originating from the microbial loop by copepod feeding directly on ciliates and heterotrophic dinoflagellates. Another pathway of FAs is through direct sedimentation of phytoplankton, which was observed as pigment sedimentation. The PUFA content of this material was high in spring and summer when dinoflagellates and diatoms were common. For the FA dynamics, it is important to note that the periods of significant input of PUFAs to the sediment coincides with the period of highest transformation capability by the zooplankton, which in the present study was summer and autumn.

Acknowledgements. This study was supported by FORMAS contract number 210-2008-1882 (BONUS+ project BAZOOCA) to P.T., a Marie Curie Incoming International Fellowship (EU Commission FP-6, MIF1-CT-2006-021529) to D.C. and the Danish National Science Research Council (grant no. 27207-0485) to B.W.H. We thank L. Rodríguez-Graña for assistance during field work and lipid extractions and 4 anonymous reviewers for comments.

\section{LITERATURE CITED}

Ahlgren G, Goedkoop W, Markensten H, Sonesten L, Boberg M (1997) Seasonal variations in food quality for pelagic and benthic invertebrates in Lake Erken-the role of fatty acids. Freshw Biol 38:555-570

Anderson TR, Pond DW (2000) Stoichiometric theory extended to micronutrients: comparison of the roles of essential fatty acids, carbon, and nitrogen in the nutrition of marine copepods. Limnol Oceanogr 45:1162-1167

- Brett MT, Müller-Navarra DC (1997) The role of highly unsaturated fatty acids in aquatic food web processes. Freshw Biol 38:483-499

Budge SM, Parrish CC, McKenzie CH (2001) Fatty acid composition of phytoplankton, settling particulate matter and sediments at a sheltered bivalve aquaculture site. Mar Chem 76:285-303

Calliari D, Tiselius P (2009) Organic carbon fluxes through the mesozooplankton and their variability at different time-scales in the Gullmarsfjord, Sweden. Estuar Coast Shelf Sci 85:107-117

> Claustre H, Poulet SA, Williams R, Benmlih F, Martinjezequel V, Marty JC (1992) Relationship between the qualitative nature of particles and copepod feces in the Irish Sea. Mar Chem 40:231-248

Cotonnec G, Brunet C, Sautour B, Thoumelin G (2001) Nutritive value and selection of food particles by copepods during a spring bloom of Phaeocystis sp. in the English Channel, as determined by pigment and fatty acid analyses. J Plankton Res 23:693-703

Dalsgaard J, St. John JM, Müller-Navarra DC, Hagen W (2003) Fatty acid trophic markers in the pelagic marine environment: a review. Adv Mar Biol 46:225-340

Dam HG, Peterson WT (1988) The effect of temperature on the gut clearance rate constant of planktonic copepods. J Exp Mar Biol Ecol 123:1-14

> Ding HB, Sun MY (2005) Biochemical degradation of algal fatty acids in oxic and anoxic sediment-seawater interface systems: effects of structural association and relative roles of aerobic and anaerobic bacteria. Mar Chem 93: $1-19$

Dutz J, Peters J (2008) Importance and nutritional value of large ciliates for the reproduction of Acartia clausi during the post spring-bloom period in the North Sea. Aquat Microb Ecol 50:261-277

- Evjemo JO, Tokle N, Vadstein O, Olsen Y (2008) Effect of essential dietary fatty acids on egg production and hatching success of the marine copepod Temora longicornis. J Exp Mar Biol Ecol 365:31-37

> Fenchel T (1988) Marine plankton food chains. Annu Rev Ecol Syst 19:19-38

Hamm CE, Rousseau V (2003) Composition, assimilation and degradation of Phaeocystis globosa-derived fatty acids in the North Sea. J Sea Res 50:271-283

> Hazzard SE, Kleppel GS (2003) Egg production of the copepod Acartia tonsa in Florida Bay: role of fatty acids in the nutritional composition of the food environment. Mar Ecol Prog Ser 252:199-206

Jónasdóttir SH, Gudfinnsson HG, Gislason A, Asthorsson OS (2002) Diet composition and quality for Calanus finmarchicus egg production and hatching success of south-west Iceland. Mar Biol 140:1195-1206

$>$ Kaneda T (1991) Iso- and anteiso-fatty acids in bacteria: biosynthesis, function, and taxonomic significance. Microbiol Rev 55:288-302 
Kattner G, Krause M (1989) Seasonal variations of lipids (wax esters, fatty acids and alcohols) in calanoid copepods from the North Sea. Mar Chem 26:261-275

Kiørboe T (1993) Turbulence, phytoplankton cell size, and the structure of pelagic food webs. Adv Mar Biol 29: $1-72$

Klein Breteler WCM, Schogt N, Baas M, Schouten S, Kraay GW (1999) Trophic upgrading of food quality by protozoans enhancing copepod growth: role of essential lipids. Mar Biol 135:191-198

Kreibich T, Saborowski R, Hagen W, Niehoff B (2008) Shortterm variation of nutritive and metabolic parameters in Temora longicornis females (Crustacea, Copepoda) as a response to diet shift and starvation. Helgol Mar Res 62:241-249

Leu E, Falk-Petersen S, Kwasniewski S, Wulff A, Edvardsen K, Hessen DO (2006) Fatty acid dynamics during the spring bloom in a High Arctic fjord: importance of abiotic factors versus community changes. Can J Fish Aquat Sci 63:2760-2779

Mackas D, Bohrer R (1976) Fluorescence analysis of zooplankton gut contents and an investigation of diel feeding patterns. J Exp Mar Biol Ecol 25:77-85

Mauchline J (1998) The biology of calanoid copepods. Adv Mar Biol 33:1-710

Mayor DJ, Cook K, Thornton B, Walsham P, Witte UFM, Zuur AF, Anderson TR (2011) Absorption efficiencies and basal turnover of $\mathrm{C}, \mathrm{N}$ and fatty acids in a marine Calanoid copepod. Funct Ecol 25:509-518

> Mayzaud P, Chanut JP, Ackman RG (1989) Seasonal changes of the biochemical composition of marine particulate matter with special reference to fatty acids and sterols. Mar Ecol Prog Ser 56:189-204

Parrish CC, Thompson RJ, Deibel D (2005) Lipid classes and fatty acids in plankton and settling matter during the spring bloom in a cold ocean coastal environment. Mar Ecol Prog Ser 286:57-68

Persson J, Vrede T (2006) Polyunsaturated fatty acids in

Editorial responsibility: Marsh Youngbluth,

Fort Pierce, Florida, USA zooplankton: variation due to taxonomy and trophic position. Freshw Biol 51:887-900

Pond D, Harris R, Head R, Harbour D (1996) Environmental and nutritional factors determining seasonal variability in the fecundity and egg viability of Calanus helgolandicus in coastal waters off Plymouth, UK. Mar Ecol Prog Ser 143:45-63

Reuss N, Poulsen LK (2002) Evaluation of fatty acids as biomarkers for a natural plankton community. A field study of a spring bloom and a post-bloom period off West Greenland. Mar Biol 141:423-434

Rose K, Roff JC, Hopcroft RP (2004) Production of Penilia avirostris in Kingston harbour, Jamaica. J Plankton Res 26:605-615

Sargent JR, Falk-Petersen S (1988) The lipid biochemistry of calanoid copepods. Hydrobiologia 167/168:101-114

Skerratt JH, Nichols PD, McMeekin TA, Burton H (1995) Seasonal and inter-annual changes in planktonic biomass and community structure in eastern Antarctica using signature lipids. Mar Chem 51:93-113

Tiselius P, Kuylenstierna M (1996) Growth and decline of a diatom spring bloom: phytoplankton species composition, formation of marine snow and the role of heterotrophic dinoflagellates. J Plankton Res 18:133-155

> Urban-Rich J, Hansell DA, Roman MR (1998) Analysis of copepod fecal pellet carbon using a high temperature combustion method. Mar Ecol Prog Ser 171:199-208

> Vargas CA, Tönnesson K, Sell A, Maar M and others (2002) Importance of copepods versus appendicularians in vertical carbon fluxes in a Swedish fjord. Mar Ecol Prog Ser 241:125-138

- Vargas CA, Escribano R, Poulet SA (2006) Phytoplankton food quality determines time windows for successful zooplankton reproductive pulses. Ecology 87:2992-2999

> Waite AM, Gustafsson Ö, Lindahl O, Tiselius P (2005) Linking ecosystem dynamics and biogeochemistry: sinking fractionation of organic carbon in a Swedish fjord. Limnol Oceanogr 50:658-671

Submitted: January 10, 2011; Accepted: November 3, 2011 Proofs received from author(s): January 18, 2012 